\title{
Pulmonary hypertension in chronic interstitial lung diseases
}

\author{
Antonella Caminati, Roberto Cassandro and Sergio Harari
}

Affiliations: U.O. di Pneumologia e Terapia Semi-Intensiva Respiratoria, Servizio di Fisiopatologia Respiratoria ed Emodinamica Polmonare, Ospedale San Giuseppe - MultiMedica, Milan, Italy.

Correspondence: S. Harari, U.O. di Pneumologia, Ospedale San Giuseppe - MultiMedica, via San Vittore 12. 20123 Milan, Italy. E-mail: shararidilpolmone.it

ABSTRACT Pulmonary hypertension (PH) is a common complication of interstitial lung diseases (ILDs), particularly in idiopathic pulmonary fibrosis and ILD associated with connective tissue disease. However, other lung diseases, such as combined pulmonary fibrosis and emphysema syndrome, pulmonary Langerhans cell histiocytosis, and lymphangioleiomyomatosis, may also include $\mathrm{PH}$ in their clinical manifestations. In all of these diseases, $\mathrm{PH}$ is associated with reduced exercise capacity and poor prognosis. The degree of $\mathrm{PH}$ in ILDs is typically mild-to-moderate. However, some of these patients may develop a disproportionate increase in $\mathrm{PH}$ that cannot be justified solely by hypoxia and parenchymal injury: this condition has been termed "out-of-proportion" $\mathrm{PH}$. The pathogenesis of $\mathrm{PH}$ in these diseases is various, incompletely understood and may be multifactorial. The clinical suspicion (i.e. increased dyspnoea, low diffusion capacity) and echocardiographic assessment are the first steps towards proper diagnosis of $\mathrm{PH}$; however, right heart catheterisation remains the current gold standard for diagnosis of $\mathrm{PH}$. At present, no specific therapies have been approved for the treatment of $\mathrm{PH}$ in patients with ILDs.

0 @ERSpublications

PH is a common complication of ILDs, currently no specific therapies are approved for treatment of $\mathrm{PH}$ in these patients http://ow.ly/mRaGt

\section{Introduction}

Pulmonary hypertension $(\mathrm{PH})$, defined as a resting mean pulmonary artery pressure (PAP) $\geqslant 25 \mathrm{mmHg}$, is an important complication of several interstitial lung diseases (ILDs) and can adversely affect patient outcome. Studies investigating the occurrence of PH in ILD have focused on specific population groups, such as lung transplant candidates with idiopathic pulmonary fibrosis (IPF) $[1,2]$ and patients with sarcoidosis $[3,4]$ or scleroderma-related ILD $[5,6]$. The prevalence of PH in patients with ILD varies greatly according to the underlying disease, the severity of the disease and the diagnostic approach used to identify $\mathrm{PH}$. In a recent study [7], 14\% of 212 patients with mixed types of ILD, who were screened for PH by echocardiography at a tertiary referral centre in Denmark, were diagnosed with PH: $8 \%$ of them had mild PH (mean PAP $\geqslant 25 \mathrm{mmHg}$ but $<35 \mathrm{mmHg}$ ) and $6 \%$ of them had severe PH (mean PAP $\geqslant 35 \mathrm{mmHg}$ ), as confirmed by right heart catheterisation (RHC). The gold standard for diagnosis of PH is RHC [8]. Despite some limitations and inaccuracies [9, 10], echocardiography remains the best noninvasive screening tool for PH [11].

In this review we will focus on studies reporting data on frequency, diagnosis, prognosis and treatment of PH in patients with IPF; however, we will also briefly review the literature on patients with PH associated with other ILDs.

Received: May 052013 | Accepted after revision: May 272013

Conflict of interest: Disclosures can be found alongside the online version of this article at err.ersjournals.com

Provenance: Publication of this peer-reviewed article was supported by the World Scleroderma Foundation, Switzerland (principal sponsor, European Respiratory Review issue 129).

Copyright @ERS 2013 


\section{Prevalence of PH in IPF}

IPF is defined as a chronic ILD of unknown aetiology, characterised by progressive and irreversible parenchymal fibrosis [12] and associated with poor prognosis, limited therapeutic options and reduced quality of life [13]. According to the Dana Point Classification, PH in IPF falls into the group III ("pulmonary hypertension due to lung diseases and/or hypoxemia") classification of PH [8]. The prevalence of PH in IPF remains undefined, with estimates that vary widely between studies due to differences in patient populations, underlying disease severity and diagnostic modalities.

The epidemiology of PH in IPF is not well described due to several factors. First, IPF is an insidious disease, so $\mathrm{PH}$ is usually diagnosed at an advanced stage of the disease, thus making the incidence of $\mathrm{PH}$ in the setting of IPF difficult to study. Secondly, although the gold standard for the diagnosis of PH is RHC, which is an invasive and expensive test precluding longitudinal follow-up studies, a variety of assessment methods to diagnose PH and criteria for defining PH have been used in different studies $[1,14,15]$. Lastly, most of the data has been obtained from studies conducted on patients referred as candidates for lung transplant, probably because the diagnostic assessments for these patients always include RHC. Lung transplant candidates represent a specific patient population, which includes younger subjects, patients without significant medical comorbidities and with more severe disease. Therefore, the results from candidates for lung transplantation cannot be necessarily translated to all individuals with IPF [16].

Several retrospective analyses indicate that PH in IPF may be frequent $[1,14,15]$. In patients with IPF a pulmonary arterial enlargement on computed tomography (CT) may occur even in the absence of $\mathrm{PH}$, due to presence of fibrosis; therefore, it is an unreliable sign of PH in IPF patients (fig. 1) [17]. NADrous et al. [15] observed that PH was frequent in advanced IPF, and correlated with both low diffusing capacity of the lung for carbon monoxide (DLCO) and low resting arterial oxygen tension $\left(\mathrm{PaO}_{2}\right)$. However, these authors relied on echocardiography alone, which is known to overestimate or underestimate PAP in patients with ILD [11]. In a retrospective analysis of consecutive pre-transplant IPF patients undergoing RHC, LETTIERI et al. [1] found that PH was present in approximately a third of the study population and that even moderate increases of mean PAP $(>25 \mathrm{mmHg})$ correlated with increased mortality. In another large retrospective analysis, SHORR et al. [2] confirmed that PH was common in IPF patients who were candidates for lung transplantation and was present in about $45 \%$ of these subjects; however, severe PH (mean PAP $>35 \mathrm{mmHg}$ ) was relatively infrequent. In a prospective analysis of consecutive patients with early stage IPF undergoing initial workup with RHC and pulmonary function testing, HAMADA et al. [18] observed that the prevalence of $\mathrm{PH}$ in this patient population was as low as $8.1 \%$.

Generally, the degree of PH in IPF patients is mild-to-moderate. "Out-of-proportion" PH is defined as an unjustified degree of $\mathrm{PH}$ that occurs in patients suffering from different types of parenchymal lung diseases (e.g. chronic obstructive pulmonary disease (COPD) and IPF). The pathological manifestations in patients with IPF and out-of-proportion PH are still quite unknown, and the prevalence of out-of-proportion $\mathrm{PH}$ is still matter of debate [19]. Intuitively, severity of fibrosis and the degree of restrictive physiology should correlate with the prevalence and degree of $\mathrm{PH}$ [20]. However, it appears that $\mathrm{PH}$ may not correlate with lung volumes (forced vital capacity (FVC) in particular) in patients with IPF $[1,2,15]$; suggesting factors

FIGURE 1 High-resolution computed tomography image showing a typical pattern of idiopathic pulmonary fibrosis. Main pulmonary artery and right pulmonary artery enlargement are present. The patient was a 73-year-old, male ex-smoker.

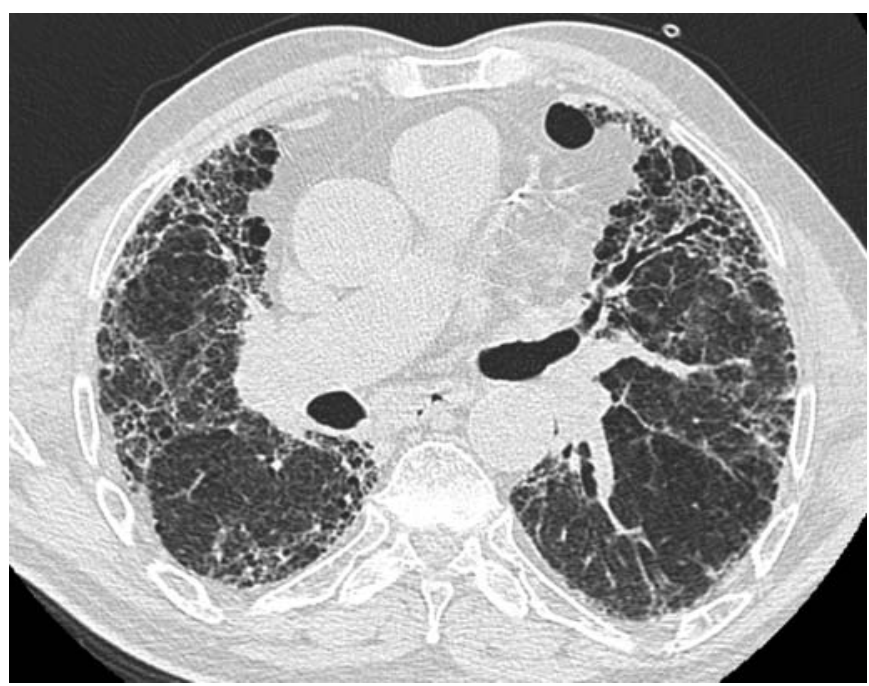


aside from progressive fibrosis are involved in the development of PH in IPF patients. Pulmonary artery remodelling might play a more relevant role than vasoconstriction, yet the two pathogenetic processes may be intimately interrelated.

\section{Diagnosis of PH in IPF}

$\mathrm{PH}$ in IPF patients is more frequent when the underlying fibrosis is severe (e.g. secondary $\mathrm{PH}$, due to parenchymal involvement). However, PH may also occur in milder disease. Since there may be key differences in pathogenesis and clinical implications of PH between the less severe forms of disease and advanced fibrosis, it has been proposed to distinguish between the two "stages" of PH in IPF: PH secondary to underlying lung disease; and disproportionate $\mathrm{PH}$ [21]. IPF patients should be evaluated for $\mathrm{PH}$ when: 1) symptoms are more severe than those expected based on lung function data (dyspnoea and fatigue are symptoms of IPF as well as PH); 2) signs of right heart failure develop; and 3) clinical deterioration is not matched by the decline in pulmonary function. Profound hypoxaemia and a low DLCO are indicators of possible $\mathrm{PH}[1]$.

In IPF patients without $\mathrm{PH}$, pulmonary function tests play a key role in the assessment of severity and progression of the disease. The question is whether particular pulmonary function profiles can predict the presence of $\mathrm{PH}$ in IPF. Routine markers for disease severity assessments (such as FVC) are useless as a detection method for PH in these patients. DLCO is reduced both in vascular and fibrotic diseases. The findings of LETTIERI et al. [1] highlighted that DLCO was lower in patients with PH (determined by RHC) than in IPF patients without PH. The combination of DLCO $<40 \%$ and a requirement for supplemental oxygen were specific, but not sensitive, for detecting PH in IPF patients undergoing evaluation for lung transplantation. Patients who met these criteria had an $87 \%$ chance of having PH. Nevertheless, patients who met none of these criteria still had an $\sim 20 \%$ chance of having PH [1].

IPF patients often have functional limitations and a decreased exercise capacity, as evaluated by the 6-min walk test $(6 \mathrm{MWT})$. In IPF patients, the distance covered in the 6MWT is considered highly reproducible [22], and the minimal clinically important difference in 6-min walking distance is between 24 and 45 metres [23]. Several studies indicate that IPF patients with PH have a significantly lower 6-min walking distance $[1,7,24-26]$; however, the role and reliability of the $6 \mathrm{MWT}$ in this clinical situation is still very controversial.

Despite some limitations, related to inadequate visualisation of all segments of the right heart and operator dependency, echocardiography remains a reliable tool for noninvasive evaluation of $\mathrm{PH}$ and is currently the recommended screening modality for early detection of $\mathrm{PH}$ [8]. Tricuspid peak flow velocity recorded by Doppler correlates well with haemodynamic parameters [27] and systolic PAP is relatively sensitive and specific for the presence of PH [21, 28]. Systolic PAP cannot be measured in the absence of tricuspid regurgitation. Although the absence of tricuspid regurgitation is rarely a problem in severe $\mathrm{PH}$, it may limit the utility of echocardiography as a tool for evaluation of mild-to-moderate $\mathrm{PH}$. In a cross-sectional study of IPF patients, NATHAN et al. [10], found that echocardiographic assessment of systolic PAP was not a sufficiently accurate test for the assessment of $\mathrm{PH}$, as nearly a third of patients with normal systolic PAP measured by echocardiography had PH, as diagnosed by RHC. A noninvasive tool that provides both high sensitivity and high specificity for detecting PH in IPF patients remains to be identified and validated. Measurements of serological markers, such as brain natriuretic peptide, might have a role in this regard, but have yet to be validated $[29,30]$. At this time, RHC remains the gold standard test for evaluation of $\mathrm{PH}$ in IPF patients.

\section{Prognostic significance of PH in IPF}

$\mathrm{PH}$ is a negative prognostic factor for IPF and other ILDs. In the view of some authors, ILD patients affected by $\mathrm{PH}$ should be listed for lung transplantation without delay [31]. In a retrospective study, LETTIERI et al. [1] reported poor outcomes in patients with advanced IPF who were affected by PH (as diagnosed by RHC). In this study, the 1-year mortality rate in IPF patients complicated by $\mathrm{PH}$ was significantly higher than that observed in lung transplant candidates without PH [1]. PATEL et al. [16] observed that PH (mean PAP $>25 \mathrm{mmHg}$ ) was an independent predictor of mortality in 376 patients with IPF referred for lung transplantation. In a recent study, KIMURA et al. [32] confirmed by multivariate analysis that a high mean PAP value measured at the initial evaluation of IPF patients undergoing RHC is an independent predictor of survival. Unlike many other studies [1,33,34], this retrospective analysis focused on IPF patients affected by milder disease (mean FVC 70.2\%, and mean DLCO 47.9\%) [32]. The study demonstrated the importance of the initial evaluation of $\mathrm{PH}$ and supported previous observations indicating that $\mathrm{PH}$ is not just a result of restrictive impairment in patients with IPF [1, 20, 35]. In the study by KIMURA et al. [32], higher mean PAP was an independent prognostic factor, comparable to FVC \% predicted, a well-known prognostic indicator in IPF. In particular, the prognosis of patients with mean PAP between 21 and $25 \mathrm{mmHg}$ and that of 
patients with mean PAP $>25 \mathrm{mmHg}$ appeared to be very similar, underlining that even "borderline" $\mathrm{PH}$ may have prognostic relevance in IPF [32].

In most studies, $\mathrm{PH}$ is quantified using the mean PAP or systolic PAP, rather than pulmonary vascular resistance (PVR). A recent study, conducted on patients with advanced fibrosing lung disease undergoing RHC, demonstrated that PVR provided discriminatory prognostic information not provided by mean PAP levels [36]. Raised PVR strongly predicted mortality within 1-year, independent of disease severity or a specific diagnosis of IPF. PVR was superior to other measurements at RHC in predicting prognosis. These findings suggest that, in advanced lung diseases, RHC could provide prognostic information with important management implications [36].

\section{Treatment}

Unfortunately, there are no approved targeted therapies for PH in IPF. Supplemental oxygen is indicated for prevention and therapy of $\mathrm{PH}$ due to hypoxia; however, there are no data supporting the beneficial effect of oxygen on survival in this group of patients. There is no clear evidence that specific therapies utilised in pulmonary arterial hypertension (PAH) can be an effective treatment for PH in IPF patients, and welldesigned prospective studies are needed before routine use of these agents can be recommended and a firm conclusion made [16, 37-43]. The Sildenafil Trial of Exercise Performance in Idiopathic Pulmonary Fibrosis (STEP-IPF study) [44] intended to evaluate the effects of sildenafil in a population with advanced IPF, defined by the severity of lung function abnormalities (DLCO $<35 \%$ predicted). The primary end-point of the study, the distance covered in the 6MWT, was not met. The study group presumably included patients with PH; however, the lack of RHC assessment before and after treatment precluded the possibility of determining whether the use of sildenafil contributed to the achievement of some benefit in secondary endpoints (e.g. decreased dyspnoea, improved quality of life and improved gas transfer) for this group of patients. Thus, it can only be assumed that the positive changes observed for secondary end-points in this study could probably reflect some improvements in PH. The subset of STEP-IPF patients with baseline echocardiogram evaluation have been reviewed in a post hoc analysis. Sildenafil treatment in patients with IPF and increased systolic PAP results in better preservation of exercise capacity and quality of life as compared with placebo [45]. The effect of ambrisentan, an endothelin-1 receptor antagonist, was studied in a prospective, multicentre, randomised, double-blinded study in PH-IPF patients. The ambrisentan PH-IPF trial was interrupted prematurely because of a lack of superior activity of the experimental arm (unpublished data). There were some limitations in these two trials, which were also observed in other studies. In particular, the primary end-point, the 6MWT distance, is a nonvalidated and probably a misleading test, and its prognostic significance is still unknown [19]; therefore, this could have complicated the result's interpretation. Also, mild PH is frequently observed in advanced IPF, whereas moderate-tosevere $\mathrm{PH}$ is rarely observed. Patients with severe $\mathrm{PH}$ (out-of-proportion $\mathrm{PH}$ ) have a completely different disease course and a very bad prognosis; therefore, these patients should be distinguished from other groups in clinical trials [19]. Another randomised, double-blind, placebo-controlled clinical trial conducted on IPF patients without $\mathrm{PH}$ was prematurely discontinued because patients treated with ambrisentan had higher incidence of disease progression (i.e. decline in respiratory function and respiratory hospitalisations) compared to patients receiving placebo [46]. The safety, tolerability and preliminary efficacy of riociguat

FIGURE 2 Subpleural intralobular interstitial thickening, reticulation, and traction bronchiectasis and initial honeycombing in a patient with systemic sclerosis. Oesophageal dilatation is present.

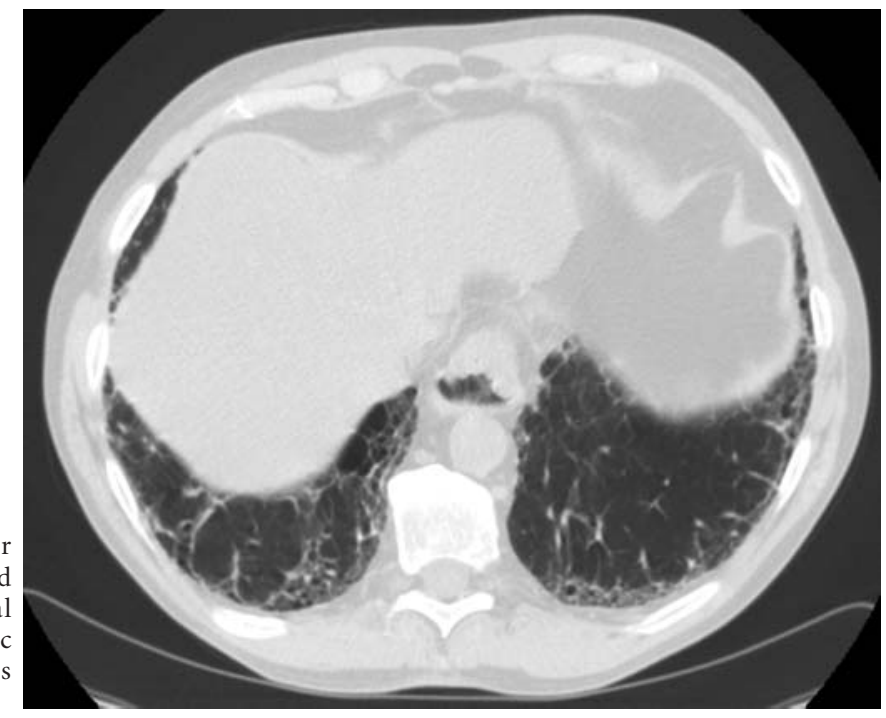



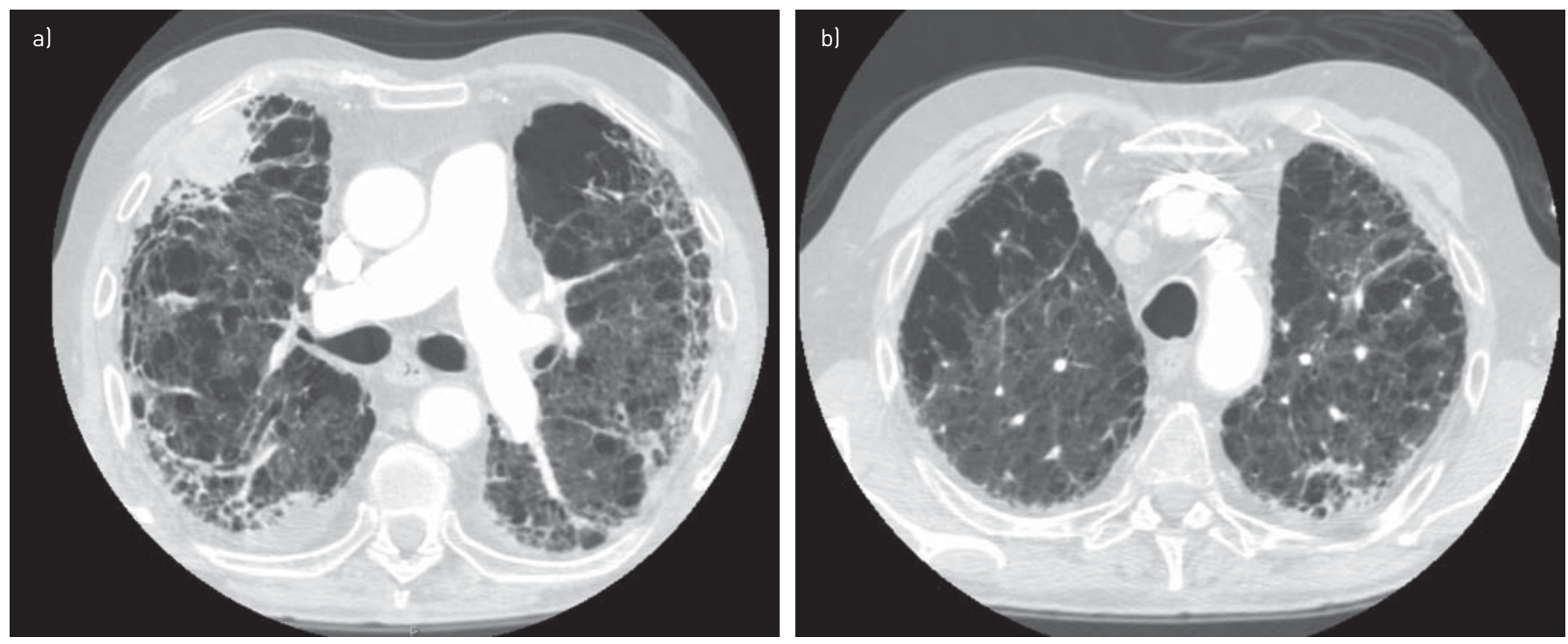

FIGURE 3 High-resolution computed tomography (HRCT) images from a 75-year-old, male ex-smoker with combined pulmonary fibrosis and emphysema syndrome (CPFE). a) HRCT image shows sub-pleural honeycombing in the middle lung, traction bronchiectasis and emphysema. On the right side a consolidation compatible with lung carcinoma is present, a frequent complication in CPFE syndrome. Echocardiography documented a pulmonary arterial pressure of $75 \mathrm{mmHg}$. b) Focal lucencies associated with paraseptal emphysema are more evident in the upper lobes in the same patient.

(a soluble guanylate cyclase stimulator) has been evaluated in an open-label, uncontrolled pilot trial in patients with PH and ILDs with some positive results. Riociguat was well tolerated and was associated with an increase in cardiac output and decrease in PVR at RHC evaluation after 12 weeks of treatment; mean PAP was unchanged [47]. Riociguat shows the potential to improve exercise capacity in some patients (evaluated using 6MWT distance) [47]. More studies are needed to clarify the role of riociguat in the therapy of PH in ILDs [48].

With the advent of newer treatment options for PAH, coupled with the lack of effective therapies for IPF, targeting PH appears attractive; however, more adequate well-designed clinical trials should be performed [48]. Prior to this, it should be clarified whether mean PAP $>35 \mathrm{mmHg}$ is the appropriate cut-off value for diagnosing disproportionate $\mathrm{PH}$, and if only patients with mild-to-moderate parenchymal involvement (and minor functional impairment) and moderate-to-severe $\mathrm{PH}$ should be considered for PH therapies.

\section{Other ILDs associated with PH}

$\mathrm{PH}$ is frequent in ILD associated with connective tissue disease (CTD), where the underlying pathology is usually a nonspecific interstitial pneumonia (NSIP) pattern. Data on the prevalence and clinical features of PH in idiopathic NSIP are sparse and basically unknown; in this setting, the level of PH is usually mild-tomoderate [49]. In an echocardiographic study, HANDA et al. [50] reported the incidence of PH to be $28 \%$ among 70 patients with idiopathic interstitial pneumonia, 11 of which had NSIP. The mean systolic PAP in this group was $30.2 \mathrm{mmHg}$. Severe PH has only rarely been described in idiopathic NSIP [51].

$\mathrm{PH}$ is a serious pulmonary complication in systemic sclerosis (SSc). Untreated SSc-PH usually results in right-sided heart failure and high risk of death. The average survival in SSc patients diagnosed with PH is 12 years $[52,53]$. Patients with SSc-PH have a worse prognosis than most other PH patients, including those with PAH [54, 55]. PH may be an isolated manifestation of SSc or may be associated with interstitial lung involvement (fig. 2). The development of PH in patients with SSc and ILD is associated with a significantly poorer prognosis [6], even worse than that of patients with singular vascular involvement [56]. A recent study showed that PAH therapies in patients with SSc-related PH complicating ILD were not associated with any clear benefits [57].

Recently, the syndrome of combined pulmonary fibrosis and emphysema (CPFE) has been described [58]. Radiological findings of CPFE include upper lobe emphysema and lower lobe fibrosis (fig. 3). This syndrome typically occurs in male smokers and is characterised by severe dyspnoea at exercise, subnormal spirometry, severely impaired DLCO and poor prognosis [59]. CPFE has also been described as a distinct pulmonary manifestation within the spectrum of CTD-associated lung diseases, such as rheumatoid arthritis and SSc [60]. It appears that $\mathrm{PH}$ is rather frequent in patients with CPFE syndrome: in the study by CotTin et al. [59] 47\% of CPFE patients had systolic PAP $\geqslant 45 \mathrm{mmHg}$, as estimated by echocardiography. $\mathrm{PH}$ seems to be more frequent in patients with CPFE than in IPF patients without emphysema [60]. $\mathrm{PH}$ is a 
characteristic feature in the natural history of CPFE syndrome $[59,61]$ and the presence of $\mathrm{PH}$ is a determinant of prognosis in these patients [60]. In a recent study $68 \%$ of the patients with CPFE syndrome were found to have $\mathrm{PH}$ (mean PAP $>35 \mathrm{mmHg}$ as detected by RHC) that was disproportionate to the underlying parenchymal lung disease [62]. Therapeutic options for patients with CPFE are limited; oxygen therapy is only used to correct hypoxaemia. Therefore, these patients should have early evaluation for lung transplant candidacy, when appropriate [62]. CотTIN et al. [62] treated patients with CPFE, on an off-label basis, with bosentan, sildenafil or inhaled iloprost, after RHC, as a first-line therapy for $\mathrm{PH}$. The evaluation performed at 3-6 months revealed that these treatments had no significant beneficial effects [62]. More adequate and well-designed prospective, randomised clinical studies are needed to evaluate the effect of these drugs in patients with $\mathrm{PH}$ and CPFE.

PH has been studied in rare pulmonary cystic diseases such as lymphangioleiomyomatosis (LAM) and pulmonary Langerhans cell histiocytosis (PLCH). LAM typically occurs in young and middle aged females (fig. 4) [63-65]. PH may occur in a small subset of LAM patients and is usually mild; in a recent study, only $20 \%$ of LAM patients had mean PAP $>35 \mathrm{mmHg}$ (out-of-proportion PH) as detected by RHC [66]. LAM patients with $\mathrm{PH}$ had mildly and severely impaired lung function, and most of them had respiratory failure requiring supplemental oxygen therapy. However, mean PAP and PVR did not correlate with $\mathrm{PaO}_{2}$, indicating that factors other than hypoxaemia could be involved in the development of PH [66]. A specific off-label therapy for PAH with bosentan or sildenafil in a subgroup of six patients significantly improved pulmonary haemodynamics without a significant difference in exercise capacity or dyspnoea [66]. These are the results of an observational and uncontrolled study with a small number of treated patients (due to rarity of the disease) and more prospective, well-designed studies are needed before definitive conclusions can be drawn.

PLCH is a smoking-related interstitial lung disease; it is commonly associated with hyperinflation and/or obstructive defects on pulmonary functional testing, and is characterised by a bronchiolocentric granulomatous inflammation (fig. 5) [67]. The course of the disease is unpredictable, as it may regress, either spontaneously or after steroid therapy and/or smoking cessation, or progress to pulmonary fibrosis and honeycombing leading to chronic respiratory failure that requires lung transplantation as the only lifesustaining option $[68,69]$. PH is frequent in patients with advanced PLCH [70], and is related to an intrinsic pulmonary vascular disease in which the pulmonary circulation is involved independent of small airway and lung parenchyma injury [71]. In the study of DAURIAT et al. [72], PH as diagnosed by RHC, was present in $92 \%$ of the 39 patients with PLCH referred for lung transplantation and was moderate-to-severe (mean PAP $\geqslant 35 \mathrm{mmHg}$ ) in $72.5 \%$ of cases. However, PH may not occur only in end-stage PLCH patients [73]. Despite similar hypoxaemia and less severe functional limitation, $\mathrm{PH}$ appears to be more frequent and more severe in PLCH than in other diseases, such as IPF and COPD, due to the intrinsic pulmonary vascular disease involving arterioles and venules leading to a variable degree of luminal obstruction, vascular remodelling and inflammation [71]. The prognosis of patients with PLCH and PH is still not well known. LE PAVEC et al. [74] recently reported that the use of PAH-specific therapies was associated with a significant improvement in haemodynamics, which remained persistently improved over time, without oxygen worsening or pulmonary oedema. A possible development of pulmonary oedema has been reported by other authors, due to the presence of pathological aspects of pulmonary veno-occlusive disease [71]; the possible occurrence of such a treatment-related complication remains a controversial topic.

$\mathrm{PH}$ is a rare complication of another lung granulomatous disease, sarcoidosis [75-77]. Although this complication is rare in absolute terms, it is not uncommon in patients with advanced disease, particularly in patients with stage III and IV disease [4]. PH in sarcoidosis is not related to the degree of lung fibrosis and

FIGURE 4 High-resolution computed tomography from a 63 -year-old, female nonsmoker with lymphangioleiomyomatosis showing diffuse thin-walled lung cysts.

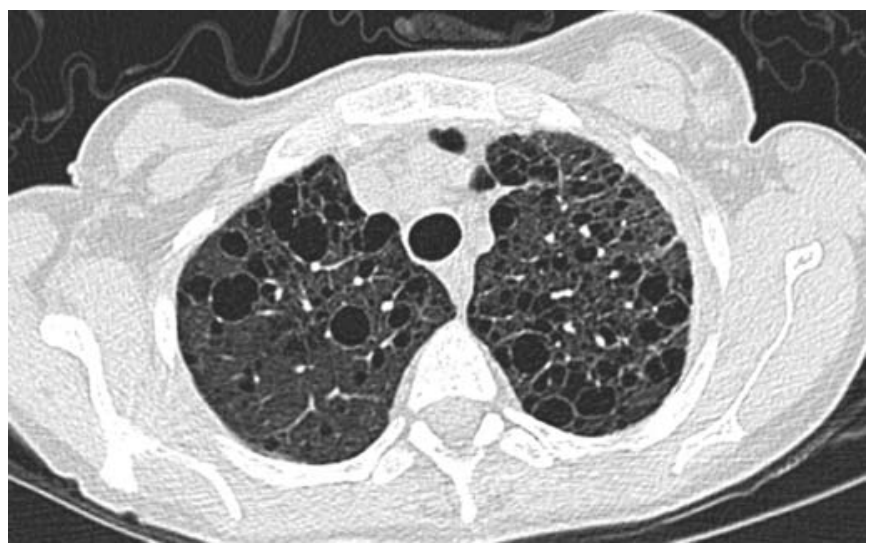




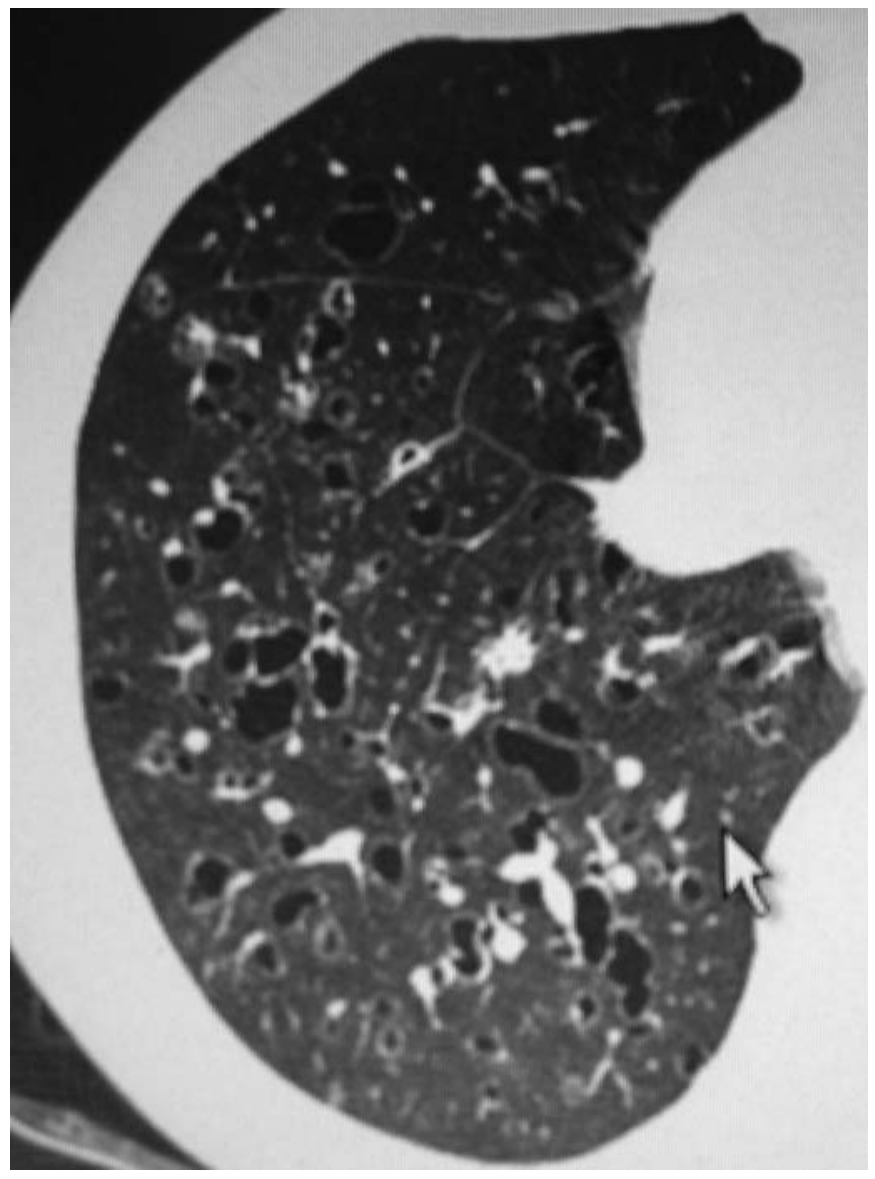

FIGURE 5 Irregular, thick- and thinwalled cysts and nodules in a patient with pulmonary Langerhans cell histiocytosis.

functional impairment [78]. NUNES et al. [78] reported that PH may develop in patients with sarcoidosis through several pathogenetic mechanisms: 1) fibrotic involvement and destruction of the capillary bed determining chronic hypoxaemia; 2) compression of large pulmonary arteries by mediastinal or hilar adenopathies or fibrosis; 3) specific granulomatous vasculitis; and 4) pulmonary vasoconstriction by release of vasoactive factors. The presence of $\mathrm{PH}$ in sarcoidosis is associated with poor outcomes [4]. In the absence of pulmonary fibrosis, corticosteroid therapy should be considered to treat $\mathrm{PH}$ complicating sarcoidosis, since it may sometime be efficacious. In patients with fibrotic disease, corticosteroids seem to be inactive and, when appropriate, these patients should have early referral for lung transplant evaluation [79, 80]. Caution should be used with vasodilator therapies in patients with $\mathrm{PH}$ in sarcoidosis due to the potential risk of developing pulmonary oedema [79, 80].

\section{Conclusions}

$\mathrm{PH}$ is a frequent and severe complication in IPF and other ILDs. PH should be suspected whenever hypoxaemia and DLCO are disproportionately low compared with functional and radiological impairment and patients show severe exercise desaturation. Echocardiographic evaluation is a preliminary step in the diagnostic work-up. RHC should always be performed in cases of suspected PH for diagnostic confirmation. The mechanisms for development of $\mathrm{PH}$ may, in part, be common to and in part specific to the different diseases. There are no effective treatments for PH in patients with IPF and other ILDs; supplemental oxygen should be prescribed according to standard guidelines. Lung transplantation, when indicated, is the only therapy that may improve survival in these patients; moreover, it is the best option in the advanced stages of disease. However, the presence of $\mathrm{PH}$ is a negative prognostic factor for lung transplantation. LAM and $\mathrm{PLCH}$ are the only ILDs complicated by the development of $\mathrm{PH}$ in which preliminary data suggest a possible effectiveness of PAH-specific therapies. Studies focused on targeted pulmonary vascular therapy, with long-term follow-up and clinically meaningful end-points (e.g. mortality and progression-free survival) are needed before a specific therapy can be recommended in these situations. Patients with ILD who are diagnosed with $\mathrm{PH}$ should be treated in a clinical trial setting whenever possible. 


\section{References}

1 Lettieri CJ, Nathan SD, Barnett SD, et al. Prevalence and outcomes of pulmonary arterial hypertension in advanced idiopathic pulmonary fibrosis. Chest 2006; 129: 746-752.

2 Shorr AF, Wainright JL, Cors CS, et al. Pulmonary hypertension in patients with pulmonary fibrosis awaiting lung transplant. Eur Respir J 2007; 30: 715-721.

3 Handa T, Nagai S, Miki S, et al. Incidence of pulmonary hypertension and its clinical relevance in patients with sarcoisosis. Chest 2006; 129: 1246-1252.

4 Shorr AF, Helman DL, Davies DB, et al. Pulmonary hypertension in advanced sarcoidosis: epidemiology and clinical characteristics. Eur Respir J 2005; 25: 783-788.

5 Chang B, Wigley FM, White B, et al. Scleroderma patients with combined pulmonary hypertension and interstitial lung disease. J Rheumatol 2003; 30: 2398-2405.

6 Launay D, Mouthon L, Hachulla E, et al. Prevalence and characteristics of moderate to severe pulmonary hypertension in systemic sclerosis with and without interstitial lung disease. J Rheumatol 2007; 34: 1005-1011.

7 Andersen CU, Mellemkjaer S, Hilberg O, et al. Pulmonary hypertension in interstitial lung disease: prevalence, prognosis and 6 min walk test. Respir Med 2012; 106: 875-882.

8 Galiè N, Hoeper MM, Humbert M, et al. Guidelines for the diagnosis and treatment of pulmonary hypertension. Eur Respir J 2009; 34: 1219-1263.

9 Arcasoy SM, Christie JD, Ferrari VA, et al. Echocardiographic assessment of pulmonary hypertension in patients with advanced lung disease. Am J Respir Crit Care Med 2003; 167: 735-740.

10 Nathan SD, Shlobin OA, Barnett SD, et al. Right ventricular systolic pressure by echocardiography as a predictor of pulmonary hypertension in idiopathic pulmonary fibrosis. Respir Med 2008; 102: 1305-1310.

11 Goto K, Arai M, Watanabe A, et al. Utility of echocardiography versus BNP level for the prediction of pulmonary arterial pressure in patients with pulmonary arterial hypertension. Int Heart J 2010; 51: 343-347.

12 Raghu G, Collard HR, Egan JJ, et al. An Official ATS/ERS/JRS/ALAT statement: idiopathic pulmonary fibrosis: evidence-based guidelines for diagnosis and management. Am J Respir Crit Care Med 2011; 183: 788-824.

13 Swigris JJ, Gould MK, Wilson SR. Health-related quality of life among patients with idiopathic pulmonary fibrosis. Chest 2005; 127: 284-294.

14 King TE Jr, Tooze JA, Schwarz MI, et al. Predicting survival in idiopathic pulmonary fibrosis: scoring system and survival model. Am J Respir Crit Care Med 2001; 164: 1171-1181.

15 Nadrous HF, Pellikka PA, Krowka MJ, et al. The impact of pulmonary hypertension on survival in patients with idiopathic pulmonary fibrosis. Chest 2005; 128: 616S-617S.

16 Patel NM, Lederer DJ, Borczuk AC, et al. Pulmonary hypertension in idiopathic pulmonary fibrosis. Chest 2007; 132: 998-1006.

17 Devaraj A, Wells AU, Meister MG, et al. The effect of diffuse pulmonary fibrosis on the reliability of CT signs of pulmonary hypertension. Radiology 2008; 249: 1042-1049.

18 Hamada K, Nagai S, Tanaka S, et al. Significance of pulmonary arterial pressure and diffusion capacity of the lung as prognosticator in patients with idiopathic pulmonary fibrosis. Chest 2007; 131: 650-656.

19 Harari S. Out-of-proportion pulmonary hypertension: a paradigm for rare diseases. Chest 2012; 142: 1087-1088.

20 Nathan SD, Noble PW, Tuder RM. Idiopathic pulmonary fibrosis and pulmonary hypertension: connecting the dots. Am J Respir Crit Care Med 2007; 175: 875-880.

21 Corte TJ, Wort SJ, Wells AU. Pulmonary hypertension in idiopathic pulmonary fibrosis: a review. Sarcoidosis Vasc Diffuse Lung Dis 2009; 26: 7-19.

22 Eaton T, Young P, Milne D, et al. Six-minute walk, maximal exercise tests: reproducibility in fibrotic interstitial pneumonia. Am J Respir Crit Care Med 2005; 171: 1150-1157.

23 du Bois RM, Weycker D, Albera C, et al. Six-minute-walk test in idiopathic pulmonary fibrosis: test validation and minimal clinically important difference. Am J Respir Crit Care Med 2011; 183: 1231-1237.

24 Modrykamien AM, Gudavalli R, McCarthy K, et al. Echocardiography, 6-minute walk distance, and distancesaturation product as predictors of pulmonary arterial hypertension in idiopathic pulmonary fibrosis. Respir Care 2010; 55: 584-588.

25 Swigris JJ, Olson AL, Shlobin OA, et al. Heart rate recovery after six-minute walk test predicts pulmonary hypertension in patients with idiopathic pulmonary fibrosis. Respirology 2011; 16: 439-445.

26 Zisman DA, Karlamangla AS, Ross DJ, et al. High-resolution chest CT findings do not predict the presence of pulmonary hypertension in advanced idiopathic pulmonary fibrosis. Chest 2007; 132: 773-779.

27 Berger M, Haimowitz A, Van Tosh A, et al. Quantitative assessment of pulmonary hypertension in patients with tricuspid regurgitation using continuous wave Doppler ultrasound. J Am Coll Cardiol 1985; 6: 359-365.

28 Barst RJ, McGoon M, Torbicki A, et al. Diagnosis and differential assessment of pulmonary arterial hypertension. J Am Coll Cardiol 2004; 43: Suppl. 12, 40S-47S.

29 Leuchte HH, Neurohr C, Baumgartner R, et al. Brain natriuretic peptide and exercise capacity in lung fibrosis and pulmonary hypertension. Am J Respir Crit Care Med 2004; 170: 360-365.

30 Leuchte $\mathrm{HH}$, Baumgartner RA, Nounou ME, et al. Brain natriuretic peptide is a prognostic parameter in chronic lung disease. Am J Respir Crit Care Med 2006; 173: 744-750.

31 Behr J, Ryu JH. Pulmonary hypertension in interstitial lung disease. Eur Respir J 2008; 31: 1357-1367.

32 Kimura $\mathrm{M}$, Taniguchi $\mathrm{H}$, Kondoh $\mathrm{T}$, et al. Pulmonary hypertension as a prognostic indicator at the initial evaluation in idiopathic pulmonary fibrosis. Respiration 2013; 85: 456-463.

33 Pitsiou G, Papakosta D, Bouros D. Pulmonary hypertension in idiopathic pulmonary fibrosis: a review. Respiration 2011; 82: 294-304.

34 Nathan SD, Shlobin OA, Ahmad S, et al. Pulmonary hypertension and pulmonary function testing in idiopathic pulmonary fibrosis. Chest 2007; 131: 657-663.

35 Kawut SM, O'Shea MK, Bartels MN, et al. Exercise testing determines survival in patients with diffuse parenchymal lung disease evaluated for lung transplantation. Respir Med 2005; 99: 1431-1439.

36 Corte TJ, Wort SJ, Gatzoulis MA, et al. Pulmonary vascular resistance predicts early mortality in patients with diffuse fibrotic lung disease and suspected pulmonary hypertension. Thorax 2009; 64: 883-888. 
Ghofrani HA, Wiedemann R, Rose F, et al. Sildenafil for treatment of lung fibrosis and pulmonary hypertension: a randomized controlled trial. Lancet 2002; 360: 895-900.

38 Olschewski H, Ghofrani HA, Walmrath D, et al. Inhaled prostacyclin and iloprost in severe pulmonary hypertension secondary to lung fibrosis. Am J Respir Crit Care Med 1999; 160: 600-607.

39 Ryu JH, Krowka MJ, Pellikka PA, et al. Pulmonary hypertension in patients with interstitial lung diseases. Mayo Clin Proc 2007; 82: 342-350.

40 Collard HR, Anstrom KJ, Schwarz MI, et al. Sildenafil improves walk distance in idiopathic pulmonary fibrosis. Chest 2007; 131: 897-899.

41 Minai OA, Sahoo D, Chapman JT, et al. Vaso-active therapy can improve 6-min walk distance in patients with pulmonary hypertension and fibrotic interstitial lung disease. Respir Med 2008; 102: 1015-1020.

42 Jackson RM, Glassberg MK, Ramos CF, et al. Sildenafil therapy and exercise tolerance in idiopathic pulmonary fibrosis. Lung 2010; 188: 115-123.

43 Badesch DB, Feldman J, Keogh A, et al. ARIES-3: ambrisentan therapy in a diverse population of patients with pulmonary hypertension. Cardiovasc Ther 2012; 30: 93-99.

44 Zisman DA, Schwarz M, Anstrom KJ, et al. A controlled trial of sildenafil in advanced idiopathic pulmonary fibrosis. N Engl J Med 2010; 363: 620-628.

45 Han MK, Bach DS, Hagan P, et al. Sildenafil preserves exercise capacity in IPF patients with right ventricular dysfunction. Chest 2013 [In press DOI: 10.1378/chest.12-1594].

46 Raghu G, Behr J, Brown KK, et al. Treatment of idiopathic pulmonary fibrosis with ambrisentan: a parallel, randomized trial. Ann Intern Med 2013; 158: 641-649.

47 Hoeper MM, Halank M, Wilkens H, et al. Riociguat for interstitial lung disease and pulmonary hypertension: a pilot trial. Eur Respir J 2013; 41: 853-860.

48 Cottin V. Treatment of pulmonary hypertension in interstitial lung disease: do not throw out the baby with the bath water. Eur Respir J 2013; 41: 781-783.

49 Ahmad S, Barnett SD, Shlobin OA, et al. Comparison of the prevalence of pulmonary arterial hypertension (PAH) in patients with idiopathic pulmonary fibrosis (IPF) and non-specific interstitial pneumonia (NSIP). Am J Respir Crit Care Med 2006; 3: S242.

50 Handa T, Nagai S, Miki S, et al. Incidence of pulmonary hypertension and its clinical relevance in patients with interstitial pneumonias: comparison between idiopathic and collagen vascular disease associated interstitial pneumonia. Intern Med 2007; 46: 831-837.

51 Hallowell RW, Reed RM, Fraig M, et al. Severe pulmonary hypertension in idiopathic nonspecific interstitial pneumonia. Pulm Circ 2012; 2: 101-106.

52 Kawut SM, Taichman DB, Archer-Chicko CL, et al. Hemodynamics and survival in patients with pulmonary arterial hypertension related to systemic sclerosis. Chest 2003; 123: 344-350.

53 Mukerjee D, St. George D, Coleiro B, et al. Prevalence and outcome in systemic sclerosis associated pulmonary arterial hypertension: application of a registry approach. Ann Rheum Dis 2003; 62: 1088-1093.

54 Girgis RE, Mathai SC, Krishnan JA, et al. Long-term outcome of bosentan treatment in idiopathic pulmonary arterial hypertension and pulmonary arterial hypertension associated with the scleroderma spectrum of diseases. J Heart Lung Transplant 2005; 24: 1626-1631.

55 Fisher MR, Mathai SC, Champion HC, et al. Clinical differences between idiopathic and scleroderma-related pulmonary hypertension. Arthritis Rheum 2006; 54: 3043-3050.

56 Launay D, Humbert M, Berezne A, et al. Clinical characteristics and survival in systemic sclerosis-related pulmonary hypertension associated with interstitial lung disease. Chest 2011; 140: 1016-1024.

57 Le Pavec J, Girgis RE, Lechtzin N, et al. Systemic sclerosis-related pulmonary hypertension associated with interstitial lung disease: impact of pulmonary arterial hypertension therapies. Arthritis Rheum 2011; 63: 2456-2464. Cottin V, Cordier JF. The syndrome of combined pulmonary fibrosis and emphysema. Chest 2009; 136 : 1-2.

59 Cottin V, Nunes H, Brillet PT, et al. Combined pulmonary fibrosis and emphysema: a distinct underrecognised entity. Eur Respir J 2005; 26: 586-593.

60 Cottin V, Nunes H, Mouthon L, et al. Combined pulmonary fibrosis and emphysema syndrome in connective tissue disease. Arthritis Rheum 2011; 63: 295-304.

61 Mejía M, Carrillo G, Rojas-Serrano J, et al. Idiopathic pulmonary fibrosis and emphysema: decreased survival associated with severe pulmonary arterial hypertension. Chest 2009; 136: 10-15.

62 Cottin V, Le Pavec J, Prévot G, et al. Pulmonary hypertension in patients with combined pulmonary fibrosis and emphysema syndrome. Eur Respir J 2010; 35: 105-111.

63 Johnson SR. Lymphangioleiomyomatosis. Eur Respir J 2006; 27: 1056-1065.

64 Johnson SR, Cordier JF, Lazor R, et al. European Respiratory Society guidelines for the diagnosis and management of lymphangioleiomyomatosis. Eur Respir J 2010; 35: 14-26.

65 Harari S, Torre O, Moss J. Lymphangioleiomyomatosis: what do we know and what are we looking for? Eur Respir Rev 2011; 20: 34-44.

66 Cottin V, Harari S, Humbert M, et al. Pulmonary hypertension in lymphangioleiomyomatosis: characteristics in 20 patients. Eur Respir J 2012; 40: 630-640.

67 Caminati A, Graziano P, Sverzellati N, et al. Smoking-related interstitial lung diseases. Pathologica 2010; 102: 525-536.

68 Vassallo R, Ryu JH, Schroeder DR, et al. Clinical outcomes of pulmonary Langerhans'-cell histiocytosis in adults. $N$ Engl J Med 2002; 346: 484-490.

69 Harari S, Simonneau G, De Juli E, et al. Prognostic value of pulmonary hypertension in patients with chronic interstitial lung disease referred for lung or heart-lung transplantation. J Heart Lung Transplant 1997; 16: 460-463.

70 Harari S, Brenot F, Barberis M, et al. Advanced pulmonary histiocytosis X is associated with severe pulmonary hypertension. Chest 1997; 111: 1142-1144.

71 Fartoukh M, Humbert M, Capron F, et al. Severe pulmonary hypertension in histiocytosis X. Am J Respir Crit Care Med 2000; 161: 216-223.

72 Dauriat G, Mal H, Thabut G, et al. Lung transplantation for pulmonary Langerhans' cell histiocytosis: a multicenter analysis. Transplantation 2006; 81: 746-750. 

hypertension complicating pulmonary Langerhans cell histiocytosis. Mayo Clin Proc 2004; 79: 1269-1275.

74 Le Pavec J, Lorillon G, Jais X, et al. Pulmonary Langerhans cell histiocytosis-associated pulmonary hypertension: clinical characteristics and impact of pulmonary arterial hypertension therapies. Chest 2012; 142: 1150-1157.

75 Gluskowski J, Hawrylkiewicz I, Zych D, et al. Pulmonary haemodynamics at rest and during exercise in patients with sarcoidosis. Respiration 1984; 46: 26-32.

76 Dobarro D, Schreiber BE, Handler C, et al. Clinical characteristics, haemodynamics and treatment of pulmonary hypertension in sarcoidosis in a single centre, and meta-analysis of the published data. Am J Cardiol 2013; 111: 278-285.

77 Nunes H, Uzunhan Y, Gille T, et al. Imaging of sarcoidosis of the airways and lung parenchyma and correlation with lung function. Eur Respir J 2012; 40: 750-765.

78 Nunes H, Humbert M, Capron F, et al. Pulmonary hypertension associated with sarcoidosis: mechanisms, haemodynamics and prognosis. Thorax 2006; 61: 68-74.

79 Nunes H, Uzunhan Y, Freynet O, et al. Pulmonary hypertension complicating sarcoidosis. Press Med 2012; 41: e303-e316.

80 Shlobin OA, Nathan SD. Management of end-stage sarcoidosis: pulmonary hypertension and lung transplantation. Eur Respir J 2012; 39: 1520-1533. 